\title{
Urnas en línea: estudio de un contexto funerario prehispánico registrado en un sector de las tierras bajas de Tucumán (Argentina)
}

\author{
3 \\ Gabriel E. Miguez", Mario A. Caria**, Ana C. Muntaner"***, \\ Lucía G. González Baroni ${ }^{* * * *}$, Rita A. Guerrero ${ }^{* * * * *}$ y \\ María J. Barazzutti*
}

\section{Resumen}

Se presentan los análisis de un contexto funerario compuesto por cuatro vasijas dispuestas en línea procedente del sitio Anta Yacu 2, ubicado en la zona de Horco Molle (Departamento Yerba Buena, Tucumán). La estrategia metodológica consistió en la excavación y registro de los contenidos internos de las vasijas y el análisis de los materiales recuperados (cerámica, huesos humanos) con el objetivo de establecer las características principales de las prácticas funerarias en este sector del piedemonte tucumano. Los resultados sugieren que los restos óseos de cuatro individuos jóvenes fueron depositados de forma secundaria en dichas vasijas (toscas y sin decoración), las cuales habrían sido enterradas hacia el año 200 a.C. Por último, se revisan e integran otros casos análogos previamente reportados para el piedemonte tucumano-salteño y se postulan algunas implicancias sobre este tipo de inhumaciones.

\section{Aligned urns: study of a pre-hispanic funerary context from a sector of the Tucumán lowlands (Argentina)}

\footnotetext{
Abstract

In this paper, we present the analysis of a funerary context composed of four urns arranged in line from the Anta Yacu 2 site, located in the area of Horco Molle (Department of Yerba Buena, Tucumán). The methodological strategy consisted in the excavation and registration of the internal contents of the urns and the analysis of the recovered materials (pottery, human bones), with the objective of establishing the

* Instituto de Arqueología y Museo, Facultad de Ciencias Naturales e Instituto Miguel Lillo, Universidad Nacional de Tucumán (UNT). San Martín 1545 (CP T400oCWE), San Miguel de Tucumán, Tucumán, Argentina. E-mail: gabrielmiguez7@hotmail.com; mjbarazzutti@yahoo.com.ar

** Instituto de Geociencias y Medioambiente (INGEMA), Facultad de Ciencias Naturales e Instituto Miguel Lillo, Universidad Nacional de Tucumán (UNT) - CONICET. Miguel Lillo 205 (CP T400oJFE), San Miguel de Tucumán, Tucumán, Argentina. E-mail: mcaria1@yahoo.com.ar

*** Facultad de Ciencias Naturales e Instituto Miguel Lillo, Universidad Nacional de Tucumán (UNT) - CONICET. Miguel Lillo 205 (CP T4000JFE), San Miguel de Tucumán, Tucumán, Argentina. E-mail: anita_muntaner@hotmail.com ****Instituto de Arqueología y Museo, Facultad de Ciencias Naturales e Instituto Miguel Lillo, Universidad Nacional de Tucumán (UNT) - CONICET. San Martín 1545 (CP T400oJFE), San Miguel de Tucumán, Tucumán, Argentina. E-mail: luciagonzalezbaroni@gmail.com

***** Facultad de Ciencias Naturales e Instituto Miguel Lillo, Universidad Nacional de Tucumán (UNT). Miguel Lillo 205 (CP T4000)FE), San Miguel de Tucumán, Tucumán, Argentina. E-mail: r7a7g@hotmail.com
}

Recibido: 3 de marzo de 2017 Aceptado: 8 de agosto de 2017

\section{Palabras clave}

Arqueología de la muerte Tierras bajas

Enterratorios en urnas Noroeste argentino
Keywords

Archaeology of death Lowlands Burials in urns Argentine Northwest 
main characteristics of funerary practices in this sector of the piedmont of Tucumán. The results suggest that these urns (rough and unrefined) contained the skeletal remains of four young individuals, which would have been buried around $200 \mathrm{BC}$ as secondary inhumations. Finally, other similar cases previously reported for the Tucumán-Salta piedmont are reviewed and integrated, and some implications for this type of burials are discussed.

\section{Introducción}

En la porción meridional de las tierras bajas del Noroeste argentino (NOA), principalmente aquella que comprende los valles bajos, piedemontes y llanuras de Tucumán y el sur de Salta, existen evidencias que permiten inferir que la mayoría de los entierros humanos prehispánicos fueron realizados en recipientes cerámicos (Berberián y Soria, 1970; Berberián, García Azcárate y Caillou, 1977; Campanella, 1936; Colaneri et al., 2003a, 2003b; Esparrica, 2003; García Azcárate y Korstanje, 1995; Gerónimo, 2003; Gómez, 1975; Heredia, 1970, 1975; Miguez, 2006, 2010; Rendace, Argañaráz Fochi, Cordomí y Cuenya, 2006; Rydén, 1936; Srur, 2008; Torres, 1921). Se han encontrado también entierros en cistas (Berberián y Soria, 1970) y otros directos en el suelo, estos últimos registrados en varios sitios (Berberián y Soria, 1970; Berberián et al., 1977; Caria, 2004; Heredia, 1970, 1975; Miguez y Caria, 2015; Pantorrilla y Núñez Regueiro, 2006; Srur, 2008; Tartusi y Núñez Regueiro, 2003; entre otros). Asimismo, se han relevado diferentes modalidades mortuorias espacialmente asociadas. Por citar solo un ejemplo, en un cementerio asignado al período de Desarrollos Regionales, cercano a la localidad de Zárate, al norte de la cuenca Tapia-Trancas, se han registrado más de 50 urnas, 13 cistas de planta circular, oval o rectangular y también entierros directos en tierra (Berberián y Soria, 1970).

En base a datos cronológicos relativos y a los pocos fechados radiocarbónicos existentes para dicha área, se observan ciertas diferencias en las tendencias temporales de las distintas modalidades funerarias señaladas (entierros en urnas, directos y en cistas). Por un lado, las inhumaciones en urnas se extienden a lo largo de un amplio rango cronológico que arrancaría unos dos siglos antes de la Era hasta momentos previos a la llegada de los europeos ( $c f$. Berberián et al., 1977; Heredia, 1975; Miguez y Caria, 2016; entre otros). Al respecto resulta interesante resaltar que el caso de mayor antigüedad es el que se analiza en este artículo. En cambio, los entierros directos parecen comenzar desde los inicios de la segunda mitad del primer milenio d.C. (Heredia, 1975). Fechados publicados para el sur del piedemonte tucumano corroborarían esta última tendencia (cf. Miguez y Caria, 2015; Pantorrilla y Núñez, 2006). Por último, los enterratorios en cistas solo han sido registrados para el mencionado sitio Zárate de asignación tardía.

Entre las diferentes formas de entierros en urnas se registraron casos de vasijas aisladas o formando grupos, vinculadas a los sitios de ocupación o conformando cementerios separados de aquellos, así como también dentro de las vasijas se han encontrado inhumaciones primarias y secundarias, simples y múltiples y con individuos de diferente sexo y edades (Berberián y Soria, 1970; Berberián et al., 1977; Campanella, 1936; Colaneri et al., 2003a, 2003b; Esparrica, 2003; Gerónimo, 2003; Heredia, 1970, 1975; Rendace et al., 2006; Rydén, 1936; Torres, 1921; entre otros).

En la zona de Horco Molle, situada en el piedemonte oriental de la Sierra San Javier (sector central del piedemonte tucumano), hasta el momento solo se han hallado contextos funerarios consistentes en inhumaciones secundarias en recipientes cerámicos. Por ejemplo, para el sitio homónimo (Horco Molle) se registró una urna 
funeraria vinculada a espacios domésticos (Maldonado, Neder, Roldán y Sampietro, 2011; Miguez y Caria 2010). En Anta Yacu 2, en cambio, se registró un conjunto asociado de urnas dispuestas en línea en el lecho de un arroyo (Miguez y Ortíz, 2011). Este artículo se enfoca precisamente en este último hallazgo y el objetivo es lograr una aproximación a las prácticas involucradas en el ritual mortuorio, como también algunos aspectos sobre la cosmovisión del grupo prehispánico, a partir del análisis de varias líneas de evidencia (cerámica, restos óseos) y de la discusión de los resultados en relación al hallazgo analizado.

\section{Aspectos teóricos}

El tratamiento de la muerte ha sido abordado en la arqueología funeraria desde diferentes enfoques teóricos. Desde perspectivas procesuales, por ejemplo, algunos investigadores han considerado que a través del estudio de las prácticas inhumatorias pueden conocerse diversos aspectos relativos a la organización social como las relaciones de parentesco, las diferencias de status o la pertenencia a determinados grupos (Binford, 1971; Tainter, 1978). Otros autores, en cambio, sostienen que las costumbres funerarias no reflejan directamente las estructuras sociales y proponen que es posible conocer las dimensiones simbólicas detrás de las prácticas funerarias, las cuales están vinculadas a la visión que una sociedad posee del mundo (Parker Pearson, 1982, 1999). Es en este último sentido que en este artículo se estudia la forma de inhumación registrada en el sitio Anta Yacu 2.

Siguiendo a Hodder (1994), se considera al estudio de la muerte como un análisis de la acción simbólica, que implica interpretar la cultura material no como un reflejo de la conducta sino más bien como producto de acciones y decisiones individuales que pueden ser estudiadas desde la materialidad por estar impregnada de significados sociales. En el ritual funerario se reconoce al difunto, que actúa como detonante de las prácticas mortuorias, y a los ejecutantes como los deudos del fallecido que tienen una participación activa al realizar las actividades involucradas en la ceremonia. Así el acto funerario activa el mundo social, simbólico y cultural de los deudos y lo materializa a través de un particular tratamiento mortuorio. La práctica funeraria como todo hecho social está históricamente situada en el tiempo, el espacio y el territorio y se encuentra estrechamente ligada a la concepción de los deudos sobre la muerte, cómo se relacionan con ella y qué uso sociocultural le otorgan (Hodder, 1994; Parker Pearson, 1999).

A través de este tipo de estudios es posible interpretar la visión que tiene un grupo social determinado sobre la muerte y las acciones que ejecuta en el tratamiento mortuorio, aunque es importante tener presente que el difunto puede ser usado por sus deudos para dirimir disputas sociales por lo que la práctica funeraria no está exenta de proporcionar una representación idealizada o distorsionada de los difuntos (Charles y Buikstra, 1995; Parker Pearson, 1999).

\section{El marco geográfico y arqueológico}

La zona de Horco Molle, situada en el Departamento Yerba Buena dentro de la provincia de Tucumán (Figura 1), comprende la porción inferior de los faldeos orientales de la Sierra San Javier y el piedemonte aledaño. Esta zona se encuentra bajo la jurisdicción de la Universidad Nacional de Tucumán (UNT). Su rango altitudinal se ubica entre los 500 y $750 \mathrm{~m}$ s.n.m. A grandes rasgos, el relieve se compone de un sector occidental de laderas con pendientes medias y altas, una porción pedemontana de pendientes moderadas a suaves con presencia de conos aluviales disectados por cursos estacionales y un sector oriental con glacis cubierto en forma de lomadas (Miguez, 2005, 2006). 


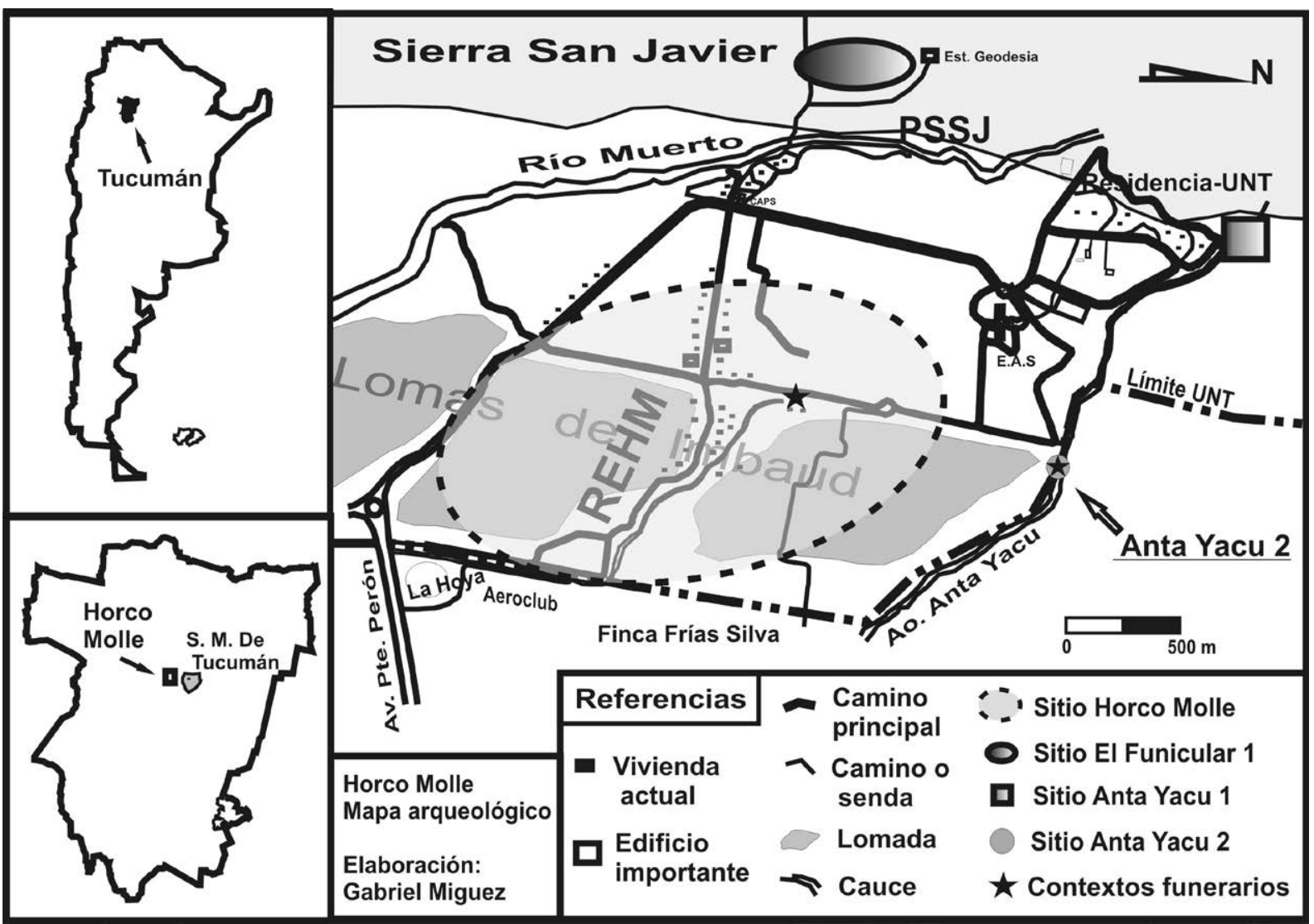

Figura 1. Mapa con la ubicación del sitio Anta Yacu 2 y de los contextos funerarios registrados en la zona de Horco Molle.

Sobre este relieve se desarrolla un ambiente modificado de las selvas subtropicales de montaña o Yungas, particularmente correspondiente a los pisos de las Selvas Pedemontana y Montana (Brown, Grau, Malizia y Grau, 2001) con un régimen de lluvias de $1.000 \mathrm{~mm}$ anuales.

Hasta el momento han sido relevados cuatro sitios arqueológicos en esta zona: Horco Molle, El Funicular 1, Anta Yacu 1 y Anta Yacu 2 (Figura 1). El Funicular 1 se ubica en un sector bajo de la ladera oriental de la Sierra San Javier y en superficie se halla conformado por fragmentos de vasijas, materiales líticos tallados, artefactos de molienda y por estructuras de piedras metamórficas en forma de alineamientos curvilíneos que dibujan formas incompletas (Miguez y Caria, 2010). En una excavación efectuada en una de estas estructuras (de forma aproximadamente oval, incompleta, en cuyo perímetro se preserva un desnivel sobre el cual se apoyan varias piedras semi-enterradas en posición vertical) se recuperaron abundantes tiestos toscos y gruesos, artefactos líticos tallados en varias materias primas (en cuarzo, metamorfitas y obsidiana), escasos restos óseos, carbón y un fragmento de hacha pulida. La escasa cerámica decorada que se halló en este sitio correspondería al estilo Candelaria.

Horco Molle es el sitio de mayor tamaño y se localiza en la porción media y distal del cono aluvial del río Muerto (Figura 1). En sectores de cumbres y laderas orientales de las lomadas se hallaron, en superficie, posibles restos de estructuras arquitectónicas mal preservadas (conformadas por rocas metamórficas semi-enterradas alineadas o dispersas) vinculados a fragmentos cerámicos, artefactos líticos tallados (en cuarzo y cuarcita) e instrumentos de molienda (en granitos y metamorfitas). En una excavación efectuada junto a un alineamiento de piedras se registró un nivel de ocupación 
prehispánica entre los 20 y $35 \mathrm{~cm}$ de profundidad, en el que se encontraron grandes tiestos y lascas de cuarzo asociados a un sedimento compactado. En otro sector ubicado al pie de una de estas lomadas, se hallaron de forma casual -por una excavación con pala mecánica- fragmentos de al menos cuatro vasijas de tamaño grande que habrían estado depositadas aproximadamente hasta los $100 \mathrm{~cm}$ por debajo de la superficie. Este hallazgo ha sido interpretado como un posible contexto funerario, si bien no se han encontrado restos óseos humanos, probablemente porque estos no se han preservado (Miguez, 2005, 2006; Miguez y Caria, 2010).

En otras excavaciones sistemáticas efectuadas en la porción distal del cono del río Muerto se registraron contextos vinculados a actividades domésticas, con abundantes fragmentos cerámicos, materiales líticos tallados, artefactos de molienda, restos óseos, carbón, entre otros (Maldonado et al., 2011; Martínez, 1994; Miguez y Caria 2010). En un sector cercano a estos espacios se rescató una urna funeraria. Se trata de una vasija globular con asas horizontales y perfil inflexionado, de factura tosca y paredes gruesas, que se encontraba depositada hasta $l o s 60 \mathrm{~cm}$ de profundidad y tapada con una roca metamórfica. En su interior se registró un conjunto de restos óseos en mal estado de preservación, correspondiente a una inhumación secundaria de tres infantes y un ajuar conformado por tres cuentas líticas y una jarra pulida zooantropomorfa, de simetría dorso-ventral, con asa vertical y apliques al pastillaje de nariz y ojos granos de café (Colaneri et al., 2003a; Miguez, 2010). De este contexto funerario se obtuvo un fechado radiocarbónico que arrojó una edad numérica de $1420 \pm 20$ años AP (UGA22275, colágeno de hueso, $\delta^{13} \mathrm{C}=-13,1 \%$ ) que calibrado con 2 sigma da un rango cronológico de 640-677 años cal A.D. (Programa CALIB REV 7.1.0, 2017). Este rango concuerda con las estimaciones que algunos autores habían realizado para este sitio en base a las características de la cerámica decorada, en su mayor parte asignable al estilo Candelaria (Maldonado et al., 2011; Miguez, 2005).

El sitio Anta Yacu 1 es poco conocido, ubicado en otro sector de la parte baja de la ladera oriental de la Sierra San Javier (al norte de El Funicular 1) en un lugar conocido como Residencia Universitaria. Allí se realizaron dos sondeos y en uno de ellos se registró una concentración de pocos fragmentos cerámicos (grandes, toscos y sin decoración) entre los 50 y los $80 \mathrm{~cm}$ de profundidad (Miguez y Caria, 2010). Hasta el momento, en este último sitio no se han hallado contextos funerarios, como tampoco en El Funicular 1.

Finalmente, cabe señalar que en otros sectores del piedemonte oriental de la Sierra San Javier, se han realizado rescates arqueológicos de urnas funerarias que fueron descubiertas de forma casual, como en el caso de la localidad de Tafí Viejo. Asimismo, en la zona de El Cadillal, próxima al área de estudio, también se han registrado varias urnas funerarias, dos de ellas (de estilo Candelaria) fechadas hacia el siglo X de la Era Cristiana (Berberián et al., 1977).

Por las características de los contextos excavados y materiales arqueológicos recuperados en los sitios Horco Molle y El Funicular 1, podemos inferir que las ocupaciones corresponderían a grupos sociales del primer milenio d.C. que practicaban la caza y la recolección (Miguez, 2005; Miguez y Caria, 2010). El fechado obtenido para el primer sitio permite ubicarlo con mayor precisión en el siglo VII d.C. En cambio, de acuerdo con el fechado que se presenta a continuación, el caso de Anta Yacu 2 se ubicaría al menos dos siglos antes del inicio de la Era Cristiana. Sin embargo, cabe resaltar la escasez de fechados radiocarbónicos para el área de estudio a pesar de las numerosas investigaciones llevadas a cabo en ella. Por esta razón existen importantes vacíos en el marco cronológico local que impiden una mejor comprensión de los procesos sociales prehispánicos. 


\section{El sitio Anta Yacu 2}

Anta Yacu 2 presenta una serie de particularidades que lo diferencian de los otros sitios registrados para la zona de Horco Molle. En primer lugar su ubicación en el paisaje, ya que se encuentra situado en el actual lecho del arroyo Anta Yacu (Figura 2). Se trata de un sitio enterrado que quedó expuesto debido a la dinámica erosiva de este cauce estacional. El sector del arroyo donde este se ubica estaba desprovisto del depósito de rocas que naturalmente cubre el lecho - tal como sucede con la mayoría de los cursos de agua del piedemonte tucumano-, debido a las actividades de extracción de áridos. Como consecuencia, las precipitaciones generaron procesos de erosión lineal que desarrollaron surcos y cárcavas, algunas de grandes dimensiones, en los depósitos inferiores del cauce. La escasa presencia de rocas y los perfiles de dichas cárcavas posibilitaron la identificación de un sedimento loésico de color marrón claro que afloraba en la superficie del lecho y en el perfil de su ribera meridional y que se interpretó como un posible paleosuelo.

La intervención arqueológica de rescate llevada a cabo en este lugar se inició con una prospección superficial que consistió en la inspección ocular del lecho y los perfiles de las riberas del arroyo y la recolección indiscriminada de los restos detectados. Se observaron fragmentos cerámicos que se hallaban dispersos en un área de $15 \mathrm{~m}^{2}$ en la superficie del arroyo y también en su ribera meridional -a una profundidad de entre 2 y $3 \mathrm{~m}$ desde la altura máxima del perfil, parámetro que varía a lo largo de este sector del arroyo-. También se identificó la parte superior de una de las vasijas que conformaban el contexto funerario. No se detectaron estructuras arquitectónicas ni otros tipos de restos. Los materiales culturales registrados se hallaban vinculados al mencionado paleosuelo, lo que indica que el sitio continúa su extensión por debajo de los profundos depósitos sedimentarios observados en el mencionado perfil del arroyo.

Un análisis preliminar efectuado sobre el total de los fragmentos cerámicos recuperados en superficie $(\mathrm{n}=101)$, determinó que la muestra se compone de seis bordes (rectos a levemente evertidos) y 95 partes del cuerpo de escaso grosor $(7-10 \mathrm{~mm})$. Son todos de factura tosca, con superficies externas e internas alisadas, en algunos casos con un baño de color grisáceo $(n=4)$. Los colores de las superficies varían entre marrón, anaranjado y gris. Algunos tiestos poseen impresiones de dedos y marcas de elementos vegetales que pudieron haberse utilizado para el alisado. La pasta, de fractura irregular, posee abundantes inclusiones de clastos metamórficos y en menor medida de granos de cuarzo. La cocción es principalmente reductora y muy pocos tiestos presentan incisiones en forma de líneas aisladas, que podrían interpretarse como elementos decorativos.

Posteriormente se llevó a cabo una excavación en el sector oriental del sitio, donde afloraba la parte superior de una de las vasijas (Figura 2). El tamaño inicial de la intervención tenía $1 \mathrm{~m}^{2}$ porque el objetivo era recuperar dicho artefacto. Luego, durante el proceso de excavación, esa superficie fue aumentando debido a que se fueron hallando otros recipientes cerámicos, llegando a tener como longitudes máximas 2,25 m en dirección N-S por 1,30 m de O-E. Por lo general, en los sitios del área de estudio no suelen observarse diferencias en las capas de sedimentos, razón por la cual se decidió excavar en niveles artificiales de $10 \mathrm{~cm}$, llegándose a una profundidad máxima de $60 \mathrm{~cm}$. Finalmente, se exhumaron cuatro vasijas (enumeradas como 1, 2, 3 y 4 por orden de aparición) alineadas en dirección N-S y estrechamente vinculadas entre sí (Figura 3), ya que las distancias entre ellas se ubican en un rango de entre 5 y $15 \mathrm{~cm}$ (Miguez y Ortíz, 2011). Las bases de las mismas se hallaban prácticamente a una misma profundidad, entre los $45-50 \mathrm{~cm}$ (nivel 5). Estaban muy fragmentadas y ninguna poseía sus partes superiores (bordes, cuello y parte del cuerpo). Una de ellas (vasija 4) apareció seccionada longitudinalmente debido a la erosión hídrica que 


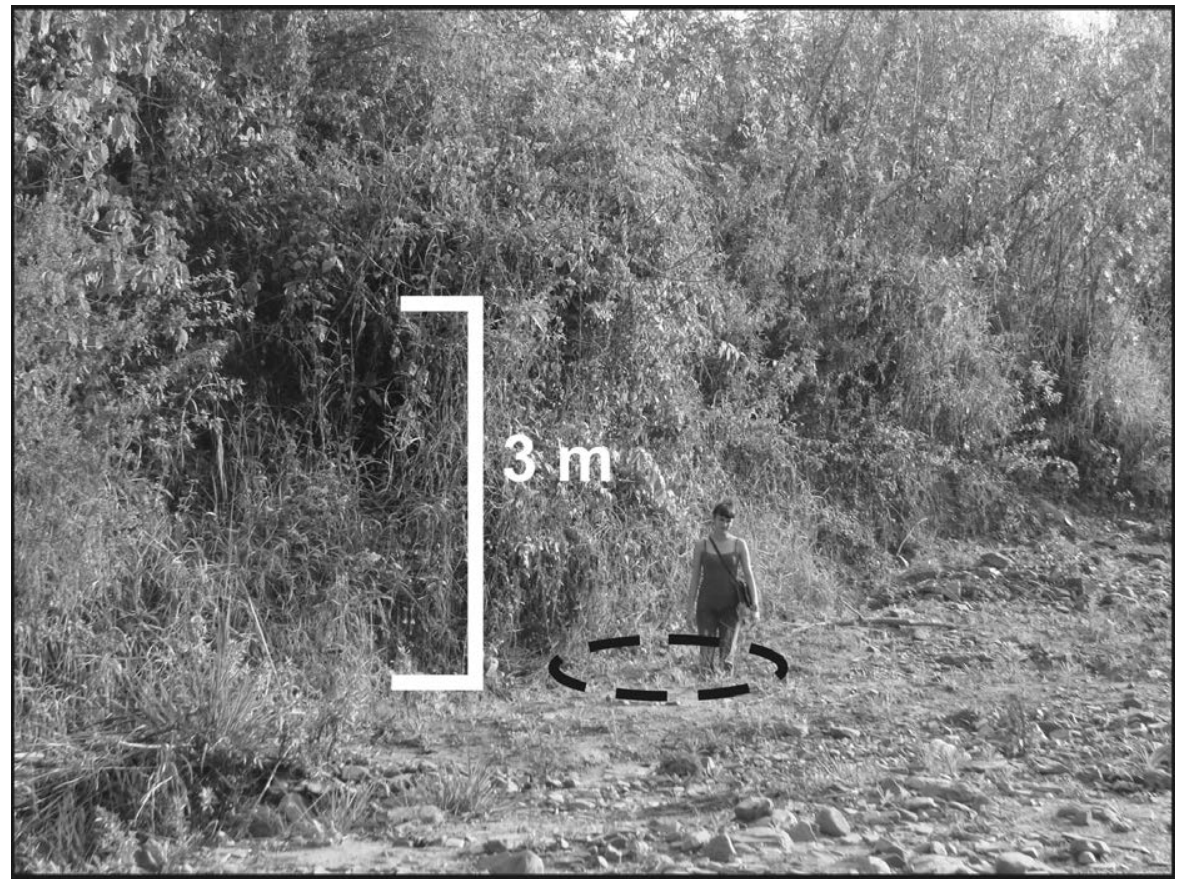

Figura 2. Vista del sitio Anta Yacu 2. En línea punteada se indica el sector específico donde se hallaron las urnas alineadas.

produjo la cárcava ubicada en el lado sur de la excavación. No se encontraron otros elementos culturales en esta intervención más que una concentración de cenizas y carbones sobre el límite occidental de la trinchera entre los 5 y $10 \mathrm{~cm}$ de profundidad (nivel 1). Finalizada la intervención las vasijas fueron embaladas con sus contenidos preservados, con el propósito de que fueran excavados en el laboratorio del Instituto de Arqueología y Museo de la UNT.

Un fechado realizado sobre uno de los huesos recuperados en la vasija 3 arrojó una dad de $2190 \pm 20$ años ${ }^{14} \mathrm{C}$ AP (UGA22274, hueso, $\delta^{13} \mathrm{C}=-8,1 \%$ ) y su rango de edad calibrada (2 sigma) es de 233-128 años cal a.C. (Programa CALIB REV 7.1.0, 2017). Constituye una de las dataciones más tempranas para el piedemonte tucumano y permite ubicar a este sitio en un momento anterior al primer milenio después de Cristo.

\section{Metodología analítica}

Con el objetivo de obtener información que permita la reconstrucción de las prácticas involucradas en el ritual funerario se llevaron a cabo diferentes tareas de laboratorio donde se registraron los contenidos internos de los recipientes y caracterizaron los materiales que conforman este hallazgo.

En primer lugar se llevó a cabo la excavación de los sedimentos internos de todas las vasijas, los cuales fueron removidos de forma cuidadosa con estecas y pinceles. Para llevar un mejor control del registro se utilizaron dos niveles artificiales correspondientes a la mitad superior e inferior del contenido internos de los recipientes. A medida que iban apareciendo restos arqueológicos, se llevó a cabo el registro del tipo de material, estado, posición (horizontal, vertical, oblicua), ubicación (en el interior de la vasija) y situación relativa con respecto a otros materiales, entre otros datos, efectuándose el relevamiento fotográfico correspondiente. Se tomaron muestras sedimentarias de los depósitos vinculados a las bases de las vasijas, las cuales todavía no fueron analizadas. 


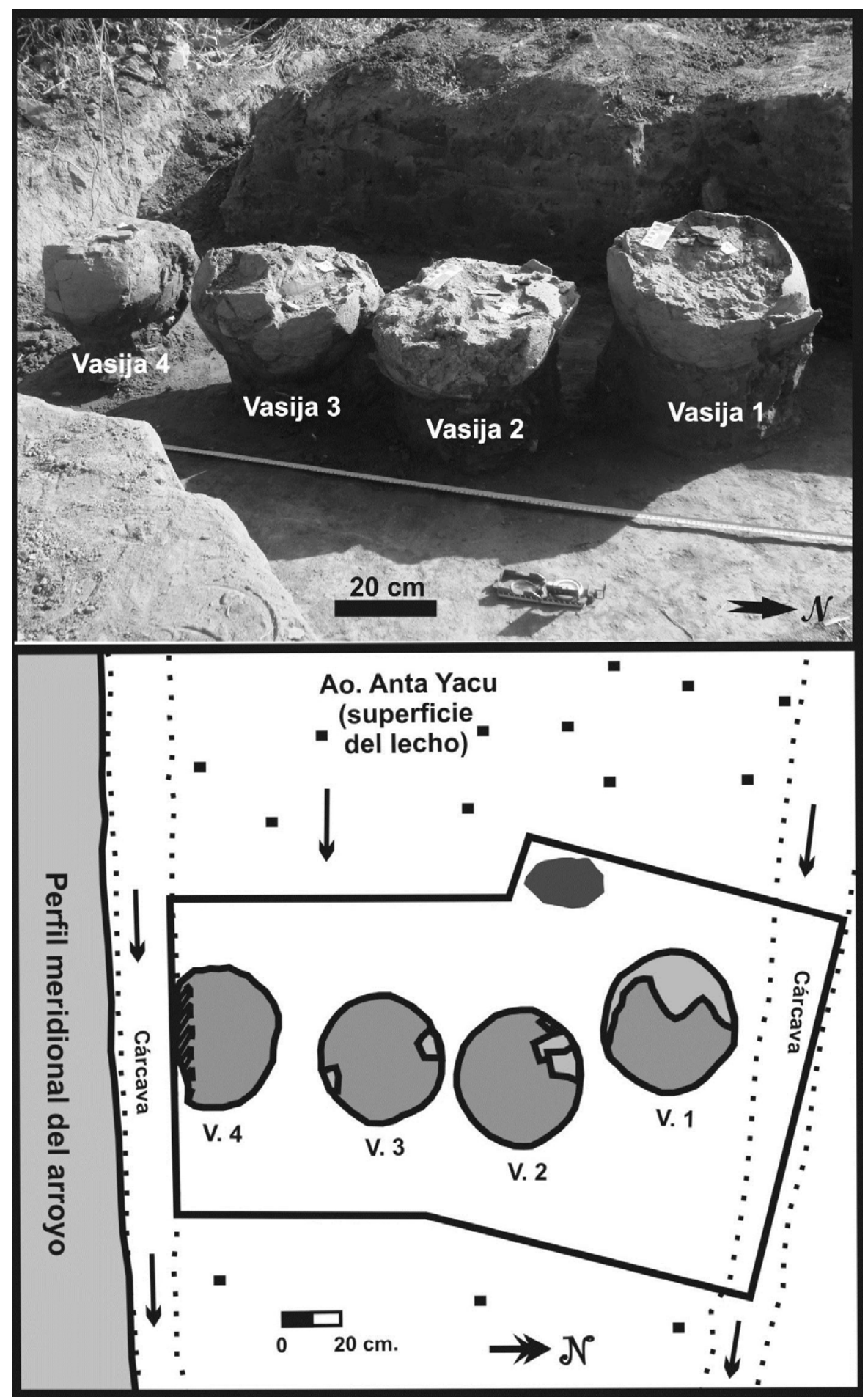

Referencias:

Fragmentos cerámicos Lente de ceniza con carbón (prof. 5-10 cm)

D Area excavada (prof. máxima: $60 \mathrm{~cm}$ )

Vasijas: en gris claro las partes del recipiente, en gris oscuro el sedimento interno (prof. en la base de las vasijas: $45-50 \mathrm{~cm}$ ) 
Se realizó también un análisis ceramológico de las vasijas centrado en variables formales y tecnológicas. Para las formas generales (contornos de los recipientes) como de las partes representadas de las vasijas se siguieron los criterios expuestos en la Primera Convención Nacional de Antropología (1966) y en Balfet, Fauvet-Berthelot y Monzón (1992). Para la caracterización tecnológica se consideraron recomendaciones explicitadas en Cremonte y Bugliani (2006). En tal sentido se realizaron observaciones macroscópicas a ojo desnudo y con lupa de bajo aumento (15x) de los fragmentos (espesores de las paredes, color y tratamiento en ambas superficies) y de las pastas (fractura, color, cocción y características de las inclusiones no plásticas, como los tipos de materias primas, granulometría y abundancia).

El material óseo recuperado del interior de las vasijas fue manipulado siguiendo el protocolo propuesto por Aranda y Raimundo (2010). Como primera medida se realizó la limpieza mecánica y en seco para retirarles el sedimento, utilizando pinceles de distinta dureza y estecas. En los casos donde la tierra se hallaba fuertemente adherida al hueso fue necesario el uso de agua destilada. Durante el proceso de análisis se aplicó un remontaje mecánico en los huesos que estaban fracturados, para facilitar la identificación anatómica de las porciones óseas. Luego del análisis y registro fotográfico de los restos, cada porción anatómica identificada fue guardada en bolsas ziploc (libres de ácido), las cuales fueron etiquetadas con los datos correspondientes. Dadas las características de la muestra no se realizó el siglado del material ni se aplicaron técnicas de consolidación.

El análisis bioarqueológico de los restos óseos consistió en la identificación anatómica y la determinación del Número Mínimo de Individuos (NMI) teniendo en cuenta la lateralidad, tamaño y robusticidad de las partes óseas (Adams y Bird, 2008; Luna, 2008). También se calcularon medidas de abundancia taxonómica y relativa como el NISP, el NME (Número Mínimo de Elementos), MAU (Unidad Anatómica Mínima), el índice de fragmentación y el índice de integridad esqueletal. Para este último índice se contabilizaron los elementos óseos de un esqueleto completo en adultos y subadultos (179 huesos y 214 huesos, respectivamente) (Scheuer y Black, 2000; White y Folkens, 1991). Para establecer el NISP se contabilizaron todos los fragmentos de huesos. El MAU se calculó para cada unidad anatómica dividiendo el MNE por su frecuencia en un esqueleto completo. El índice de fragmentación permite conocer cuáles son los huesos más fragmentados y cuales los más enteros y se obtuvo calculando el NME por el NISP (Mondini, 2003). Para la estimación de la edad en subadultos se utilizó la secuencia de erupción dentaria y, en los casos en los que fue posible, el grado de fusión de las epífisis de los huesos largos (Buikstra y Ubelaker, 1994; Campillo y Subirá, 2004; Rouvière y Delmas, 1956). Las piezas óseas fueron situadas en intervalos etarios: fetal ( $<0$ años), infantes (0-3 años), niños (3-12 años), adolescentes (12-20 años), adultos jóvenes (20-34 años), adultos medios (35-50 años) y adultos mayores (más de 50 años) (Buikstra y Ubelaker, 1994). Para la determinación sexual se llevaron a cabo observaciones macroscópicas sobre indicadores morfológicos comúnmente utilizados en los estudios bioarqueológicos, como las características formales de la mandíbula y otras partes del cráneo y de la pelvis, entre otros (Buikstra y Ubelaker, 1994). Por último, para la identificación de lesiones paleopatológicas y marcas de corte antrópicas se siguió a Buikstra y Ubelaker (1994) y a Botella, Aleman y Jimenez (2000).

\section{Resultados}

\section{Caracterización morfo-tecnológica de las vasijas}

Cabe destacar que todas las vasijas se hallaban muy fragmentadas y algunas fuertemente deformadas. Los tiestos analizados se fueron desprendiendo a medida que se excavaba 
el sedimento. Solo en el caso de la vasija 3, en base a las medidas tomadas en forma previa a su excavación (altura máxima, diámetros máximos de base y cuerpo) pudo estimarse su forma para su reconstrucción gráfica (Figura 4A), ya que se presentaba como una de las más completas.

Los resultados del análisis de los aspectos morfológicos y tecnológicos de las vasijas (Tabla 1) permiten concluir que en todos los casos se trata de una alfarería similar, con ciertas características distintivas de la arqueología local. Principalmente se destacan el grosor de las paredes (entre 5 y $7 \mathrm{~mm}$ ) y la frecuente presencia de granos gruesos de cuarzo. Aunque las cuatro vasijas están incompletas, en al menos dos de ellas se ha podido inferir sus formas ovoides. Las dos restantes parecen haber tenido una forma similar. Además, todas fueron manufacturadas mediante la técnica de enrollamiento anular, tienen bases redondeadas y ninguna posee asas. Buena parte de los datos obtenidos nos sugieren que estas vasijas tendrían escasa ductilidad para usos domésticos. Por último cabe agregar que algunos tiestos de las bases presentan residuos de color negro en sus superficies internas, principalmente en las vasijas 2,3 y 4 .

\section{Caracterización de los contextos internos de las urnas y de sus restos óseos}

Se describen y detallan los resultados del análisis bioarqueológico para cada vasija. Es importante mencionar que el examen de los restos óseos se vio limitado por el mal estado de preservación y la elevada fragmentación de los huesos, ya que estos se presentan exfoliados, deformados, aplastados y fisurados por la acción de los procesos postdepositacionales naturales.

\section{Vasija 1}

Los primeros restos comenzaron a encontrarse en los inicios de la mitad inferior (20 $\mathrm{cm}$ ) del sedimento excavado en el recipiente. Se registraron fragmentos óseos y huesos largos, asociados a fragmentos cerámicos correspondientes a la misma vasija. En el tercio final de la vasija, se hallaron partes de un cráneo (coherentemente ubicadas en la matriz sedimentaria pero muy mal preservadas) y fragmentos dentarios dispersos. El cráneo se encontraba apoyado en la base del recipiente. Sobre el mismo yacía un hueso largo, el más completo, y sobre éste último se ubicaban otras dos partes de extremidades dispuestas en forma paralela una de otra (Figura 4B).

El análisis de la muestra bioarqueológica recuperada de esta vasija permitió identificar un total de ocho fragmentos de dientes y 35 partes de huesos en muy mal estado de preservación e integridad, correspondientes a un individuo. De las piezas óseas, 20 pertenecen al cráneo, identificándose un fragmento de temporal (de $6 \times 3 \mathrm{~cm}$ de longitud) y otro de parietal (de 5,6 x 6,5) de lateralidad indeterminada. Los demás restos del cráneo se hallaban insertos en una matriz sedimentaria muy compacta que no pudo ser removida, motivo por el cual no fueron contabilizados ni sombreados en el gráfico de los elementos recuperados. Los huesos pertenecientes al postcráneo corresponden a los miembros inferiores. Se contabilizaron 15 fragmentos de huesos largos, seis pertenecen a la parte proximal de la tibia derecha, cinco corresponden a la porción media de la diáfisis de la tibia izquierda y los cuatro restantes (que han podido ser remontados) conforman una pieza ósea de unos $20 \mathrm{~cm}$ de longitud que ha sido identificada como la porción media de la diáfisis de un fémur posiblemente izquierdo (Tabla 2). Los restos analizados no permiten determinar el sexo del individuo por falta de elementos diagnósticos. Con respecto a la estimación de la edad, la misma se vio dificultada por el elevado grado de fragmentación de los dientes, que no permitió identificar su morfología ni el estado de los ápices radiculares. Los fragmentos de huesos largos no presentan las epífisis proximales ni distales por lo cual no se pudo 


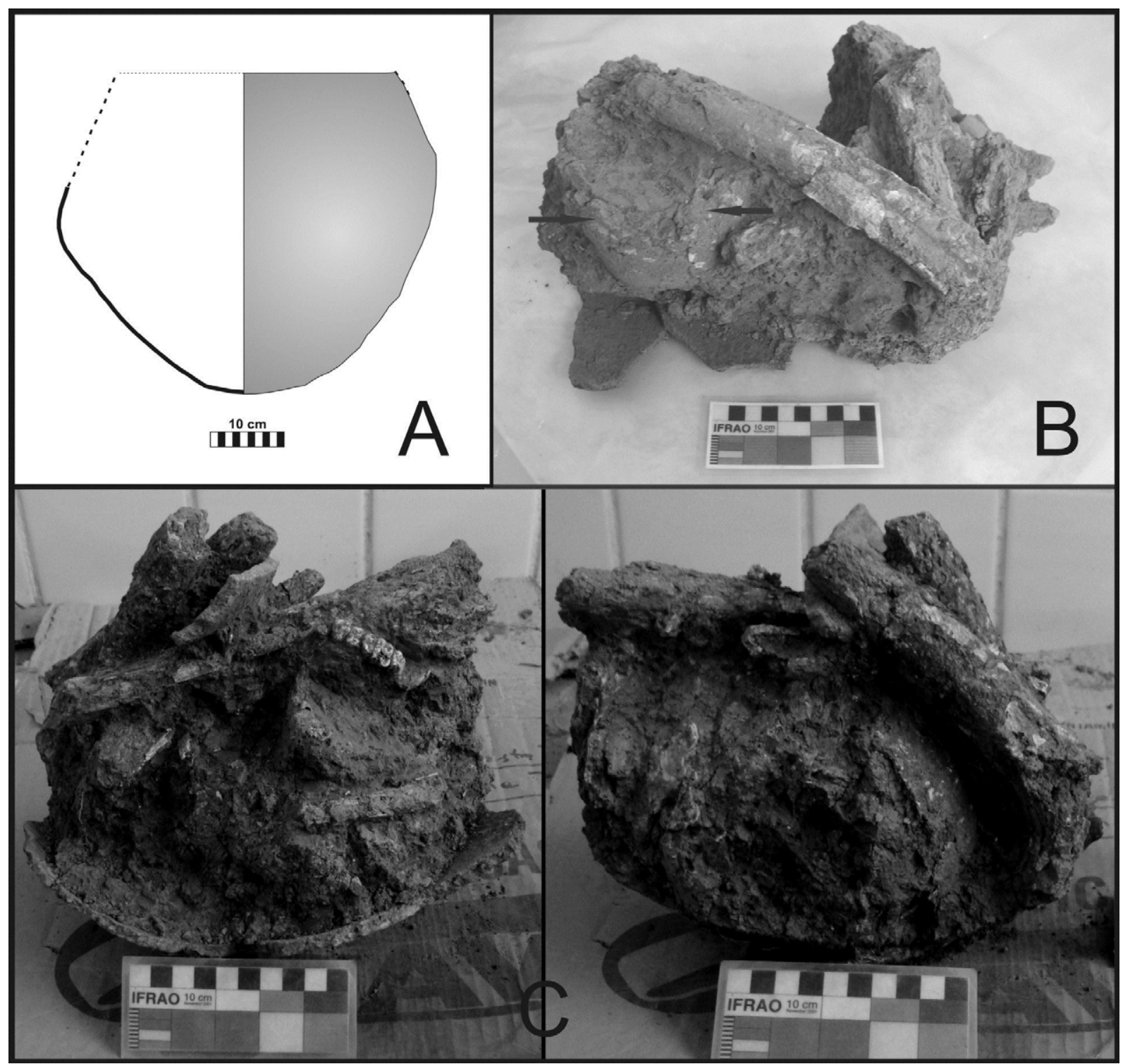

Figura 4. A- Forma estimada de vasija 3. B- Contexto registrado en vasija 1, donde se indica la ubicación del cráneo. C-Imágenes del contexto registrado en la vasija 2.

estimar la edad por los estadios de unión epifisial (Tabla 2 y Figura 5). Sin embargo, se ha podido identificar la presencia de dientes deciduos, razón por la cual se sugiere una edad estimada entre 10 y 13 años para este individuo, según los parámetros sugeridos por Ubelaker (1980).

\section{Vasija 2}

Entre los 5 y $9 \mathrm{~cm}$ del interior de la vasija se hallaron fragmentos cerámicos de la parte superior de la vasija, además de una lasca de cuarcita. Entre los 9 y $12 \mathrm{~cm}$ se registraron más fragmentos (algunos en posición vertical y otros oblicua) asociados a los extremos de dos huesos largos que aparecieron en posición vertical en el centro del recipiente. Entre los 12 y $20 \mathrm{~cm}$, además de los mencionados huesos largos (muy mal preservados y rellenos de sedimento), también se registraron otros dos en posición oblicua -también huesos largos- y seis piezas dentarias en su posición original junto 


\begin{tabular}{|c|c|c|c|c|}
\hline Variables & Vasija 1 & Vasija 2 & Vasija 3 & Vasija 4 \\
\hline Altura & $35 \mathrm{~cm}$ & $30 \mathrm{~cm}$ & $38 \mathrm{~cm}$ & $30 \mathrm{~cm}$ \\
\hline Diámetro & $46 \mathrm{~cm}$ & $45 \mathrm{~cm}$ & $53 \mathrm{~cm}$ & $44 \mathrm{~cm}$ \\
\hline Forma general & Restringida simple & Restringida simple & Restringida simple & - \\
\hline Forma geométrica del contorno & Ovoide & - & Ovaloide invertido & - \\
\hline Cantidad total de fragmentos & 220 & 177 & 218 & 129 \\
\hline $\begin{array}{l}\text { Forma de las partes } \\
\text { representadas }\end{array}$ & $\begin{array}{l}\text { Base: Cóncava } \\
\text { redondeada } \\
\text { Cuerpo: subglobular } \\
\text { Bordes: - }\end{array}$ & $\begin{array}{l}\text { Base: cóncava } \\
\text { redondeada } \\
\text { Cuerpo: subglobular } \\
\text { Bordes: rectos }\end{array}$ & $\begin{array}{l}\text { Base: cóncava } \\
\text { redondeada } \\
\text { Cuerpo: subglobular } \\
\text { Bordes: - }\end{array}$ & $\begin{array}{l}\text { Base: cóncava } \\
\text { redondeada } \\
\text { Cuerpo: subglobular } \\
\text { Bordes: - }\end{array}$ \\
\hline Grosor promedio de fragmentos & $6 \mathrm{~mm}$ & $7 \mathrm{~mm}$ & $6 \mathrm{~mm}$ & $7 \mathrm{~mm}$ \\
\hline Tratamiento de superficie & \multicolumn{4}{|l|}{ Alisado en ambas caras } \\
\hline Color de superficie & Gris a pardo marrón & $\begin{array}{l}\text { Gris a pardo marrón } \\
\text { claro }\end{array}$ & Gris a marrón & Gris a marrón \\
\hline Pasta & \multicolumn{4}{|c|}{ No compacta - fractura irregular } \\
\hline Cocción & \multicolumn{4}{|c|}{ Oxidante incompleta (gris oscuro en los núcleos a pardo anaranjados hacia las superficies) } \\
\hline Tipo de inclusiones & \multicolumn{4}{|c|}{$\begin{array}{l}\text { En todos los casos se observan abundantes clastos metamórficos de tamaños gruesos a muy } \\
\text { gruesos (1-5 mm). Mica y cuarzo en menor proporción, en tamaños más finos (ca. } 1 \mathrm{~mm} \text { ) }\end{array}$} \\
\hline
\end{tabular}

Tabla 1. Síntesis de los resultados del análisis ceramológico.

a su parte mandibular muy mal preservada (Figura 4C). También se encontraron más fragmentos cerámicos entre los restos óseos, una roca metamórfica $(14 \times 9 \mathrm{~cm})$, otras piedras de menor tamaño y pequeños carbones. En los últimos $10 \mathrm{~cm}$ aparecieron restos del cráneo (región occipital) apoyados en la base de la vasija. Estos hallazgos sugieren que el cráneo poseía su parte anterior (huesos del esplacnocráneo) mirando hacia arriba en posición oblicua y sobre él estaban depositados cuatro huesos largos (en conjuntos de pares) en posición vertical y oblicua.

En esta vasija se identificaron un total de 38 fragmentos óseos y 60 partes de piezas dentales, correspondientes a un solo individuo. Los elementos anatómicamente identificados son 11 y corresponden al poscráneo. Estos están representados por tres partes remontadas de la diáfisis proximal del fémur derecho (de $14 \mathrm{~cm}$ de longitud), tres fragmentos remontados de la porción distal de la diáfisis del fémur izquierdo (que miden en total $14 \mathrm{~cm}$ de longitud) y cinco piezas de una tibia izquierda, de las cuales luego del proceso de remontaje se pudo determinar que dos forman parte de la porción distal $(12 \mathrm{~cm}$ de longitud) y tres pertenecen a la parte proximal (19 $\mathrm{cm}$ de longitud). Se excluyeron del análisis los fragmentos de cráneo ya que, al igual que en la vasija 1, no pudieron extraerse del sedimento (Tabla 2 y Figura 5). Los huesos largos están fracturados por lo que no fue posible asignar una edad a partir de la fusión epifisaria. Con respecto al sexo no fue posible determinarlo. Con respecto a los dientes, dado el mal estado de preservación que poseían, solo se pudo identificar dos fragmentos de molares, los que por su mayor grado de integridad fueron utilizados en la estimación etaria. Dadas las características morfológicas de los mismos, se determinó que corresponderían a dientes permanentes en proceso de crecimiento cuyas raíces se encuentran ausentes, por lo que para este individuo se estima una edad aproximada entre 12 y 18 años, según los parámetros sugeridos por Ubelaker (1980).

\section{Vasija 3}

Los restos aparecen a partir de los $19 \mathrm{~cm}$ al interior de la vasija. Estos consistieron en huesos largos en posición oblicua y vertical. Apoyados en la base de la vasija 


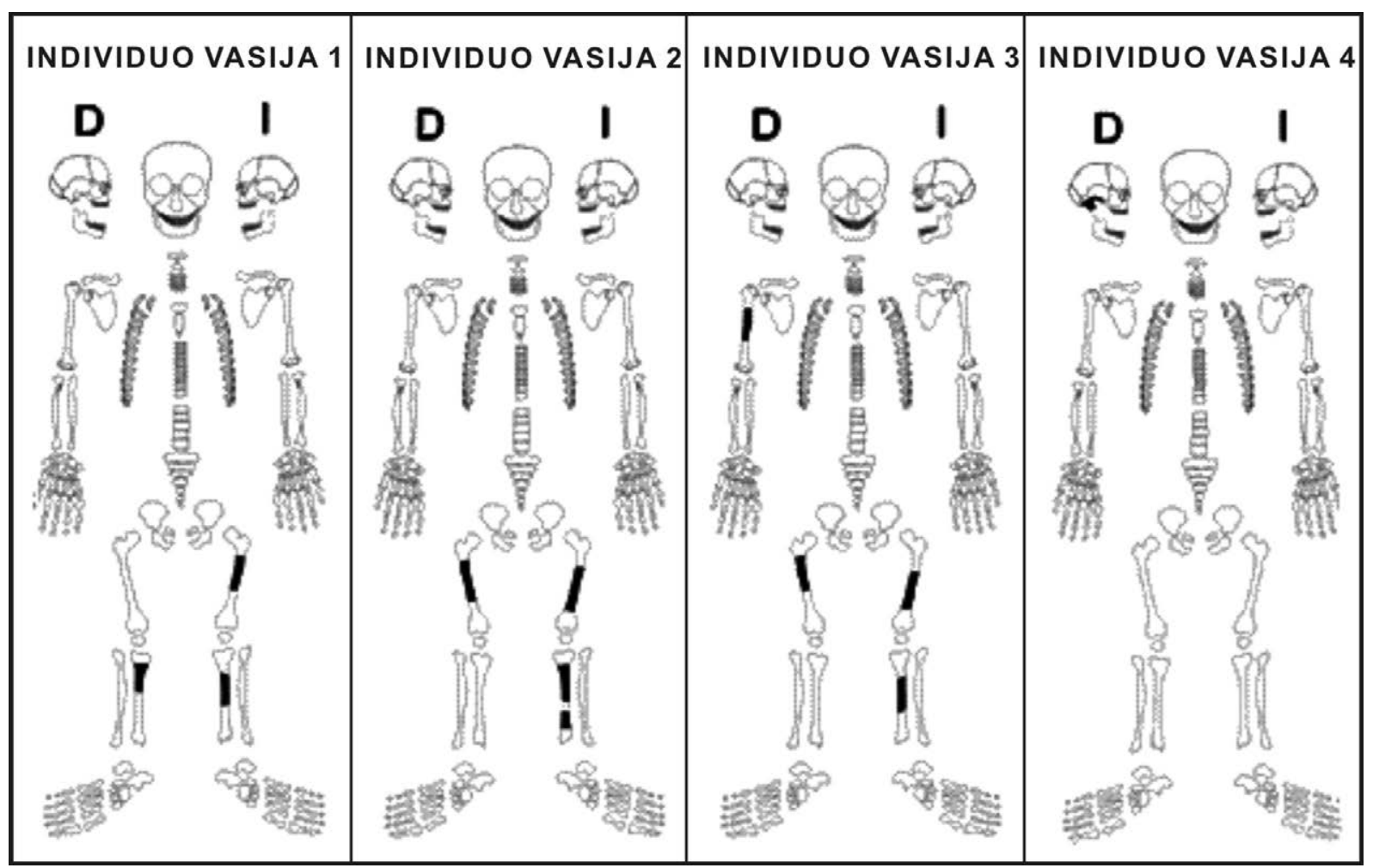

Figura 5. Representaciones de las partes esqueletarias identificadas y lateralizadas de los individuos de cada vasija.

\begin{tabular}{|l|c|c|c|c|c|c|}
\hline Partes anatómicas & NISP & NME & MAU & MAU\% & IF & \% Integridad \\
\hline Cráneo & 3 & 2 & 2 & 80 & 0,6 & 0,009 \\
Húmero & 5 & 2 & 1 & 40 & 0,4 & 0,009 \\
Fémur & 16 & 5 & 2,5 & 100 & 0,31 & 0,02 \\
Tibia & 19 & 4 & 2 & 80 & 0,21 & 0,01 \\
\hline
\end{tabular}

Tabla 2. Análisis cuantitativo del total de la muestra ósea. Nótese la baja integridad esqueletal.

(entre los 28 y los $38 \mathrm{~cm}$ de profundidad) se encontraron los restos de un cráneo y un maxilar inferior con piezas dentarias en buen estado de preservación. El fechado antes mencionado procede de este individuo (maxilar).

En el análisis bioarqueológico se contabilizaron 40 fragmentos óseos (de los que se identificaron 13 partes de piezas anatómicas) y 12 porciones de dientes, que representan un número mínimo de un individuo. De las piezas óseas ocho corresponden a fragmentos de cráneo indeterminados debido a su mal estado de preservación. Los huesos del poscráneo pertenecen a los miembros superiores e inferiores. Entre los primeros se identificaron cuatro fragmentos de húmero (de $4 \mathrm{~cm}$ de longitud cada uno) posiblemente derecho, que corresponden a la parte media de la diáfisis del hueso. Entre los miembros inferiores se determinó un fragmento de fémur posiblemente derecho (17 cm de longitud), fracturado en dos partes que no remontan; un fémur izquierdo, fragmentado en cuatro partes que remontan en una pieza de $21 \mathrm{~cm}$ de longitud, que corresponde a la porción media y distal de la diáfisis; $y$ un fragmento de tibia, posiblemente izquierda, fracturada en tres partes que no remontan. Asimismo, dentro de este conjunto se registraron 19 fragmentos óseos de huesos largos en muy mal estado de preservación que no pudieron ser asignados a una parte anatómica en particular (Tabla 2 y Figura 5). En cuanto a 
las piezas dentales, se identificaron cinco molares deciduos y siete fragmentos dentales deciduos indeterminados. Además, se registró un pequeño fragmento de maxilar inferior que conserva tres alveolos con raíces. La estimación de la edad se realizó a través de los cinco molares mejor preservados y no fue posible aplicar estadios de fusión epifisaria por falta de esta porción en los huesos largos. Los molares son deciduos e indicarían un rango de edad de entre 11 y 14 años de edad. Por las mismas razones que en los otros individuos analizados el sexo no pudo ser determinado.

\section{Vasija 4}

En la mitad superior se encontraron algunos fragmentos del mismo recipiente. A los 11 $\mathrm{cm}$ al interior de la vasija se registró una pequeña concentración de carboncillos. Desde los inicios de la mitad inferior se hallaron restos óseos muy mal preservados y también algunos fragmentos de dientes que se situaban en el centro. También se observaron algunas manchas oscuras en el sedimento. En los últimos $13 \mathrm{~cm}$ se registraron huesos largos en posición horizontal y, por debajo de ellos, los restos de un cráneo (todavía en su forma original pero muy mal preservado) que se apoyaba sobre la base del recipiente. Alrededor de estos restos óseos se encontraron otras partes de dientes. También aparecieron fragmentos cerámicos y piedras pequeñas formando parte del sedimento de relleno de la vasija.

En esta vasija se contabilizaron 50 fragmentos óseos (de los cuales se pudieron identificar dos partes anatómicas) y 33 partes de dientes. Entre los fragmentos de cráneo se identificó anatómicamente una porción de temporal derecho con apófisis mastoidea incompleta y conducto auditivo de igual lateralidad $(10 \times 8 \mathrm{~cm})$ y 25 fragmentos de cráneo indeterminados de un tamaño entre 5 y $2 \mathrm{~cm}$ de longitud. Los huesos largos están representados por 23 fragmentos en mal estado de preservación, lo que no permitió distinguir unidades anatómicas a excepción de un fragmento distal de un húmero de lateralidad indeterminada, que presenta una pequeña porción de la fosita olecraneana (Tabla 2 y Figura 5). Con respecto a las piezas dentales, se han identificado tres dientes de los cuales se distingue un canino completo permanente y dos partes de raíces indeterminadas; además de 30 fragmentos muy pequeños de dientes permanentes en proceso de crecimiento, entre los que se distinguen molares. Dada las características de la muestra, no fue fácil de establecer la estimación etaria por la ausencia de las epífisis de los huesos largos y la fragmentación de la mayoría de los dientes. Sin embargo, la presencia de un canino y dos molares permanentes, estos últimos en proceso de crecimiento, permiten estimar una edad aproximada entre $10 \mathrm{y}$ 16 años para este individuo. El sexo no fue posible de ser determinado por el elevado estado de fragmentación de la muestra sobre elementos diagnósticos como la apófisis mastoidea y la ausencia de otros huesos como la cintura pélvica.

\section{Síntesis y discusión de los resultados del caso estudiado}

A partir de los registros obtenidos se pueden realizar las siguientes observaciones. Las vasijas estaban rellenas con un sedimento homogéneo y endurecido, con piedras de diversos tamaños. En cuanto a la disposición de las partes esqueletarias pudimos observar la presencia de cráneos ubicados en el fondo de los recipientes y de piezas del esqueleto apendicular (o más bien, partes de ellas) situadas por encima de los anteriores. Varias partes dentarias fueron recuperadas asociadas (en su posición original, con o sin presencia de secciones mandibulares) o dispersas en la mitad inferior de las vasijas. En algunos casos se hallaron pequeños fragmentos de carbón. Además, cabe resaltar la presencia de manchas oscuras en el sedimento y de residuos de color negro que recubren particularmente las tibias y los fémures. 
La excavación del interior de estas vasijas, sumada al análisis bioarqueológico de sus restos óseos, permitió comprobar que se tratan de urnas funerarias. Cada una de ellas contenía restos óseos y dentales humanos en muy mal estado de preservación, teniendo en cuenta la integridad y completitud de los mismos. Se partían o se reducían a polvo con facilidad al contacto con las herramientas de excavación e incluso muchos han perdido su estructura interna, rellenándose ésta de sedimento. Sin embargo, durante el proceso de análisis osteológico ha sido posible la identificación de al menos un NMI de cuatro, es decir, de un individuo por urna. Además se reconoció la presencia de partes anatómicas correspondientes al cráneo y extremidades superiores e inferiores (Tabla 2). En la Figura 5 se puede observar que los elementos óseos con mayor representación en la muestra corresponden a fragmentos de fémures y tibias, mientras que los miembros superiores están escasamente representados (Tabla 2, Figura 5). El porcentaje de integridad esqueletal es muy bajo, no superando el $0,2 \%$ de representación ósea, lo que indica el entierro secundario de partes esqueletales. Como ya mencionamos, la estimación de la edad fue muy compleja dado el mal estado de preservación de la muestra, razón por la cual los rangos de edades de los individuos identificados son amplios, ubicándolos entre los 9 y los 18 años de edad, es decir, entre los últimos años de la niñez y la adolescencia. En ningún caso pudo ser determinado el sexo, debido a la ausencia de elementos diagnósticos y el elevado estado de fragmentación de la muestra. Por otro lado, es necesario mencionar que debido al mal estado de preservación del tejido cortical de los huesos no fue posible identificar marcas de corte y/o descarne ni patologías.

Desde el punto de vista del contexto del hallazgo, el hecho de que las vasijas estén dispuestas una al lado de la otra y a una misma profundidad sugiere la presencia de un espacio destinado para la inhumación de cuatro individuos jóvenes, tal vez en un mismo evento o ritual funerario. Sin embargo, también habría que considerar la posibilidad de que en este lugar hayan ocurrido eventos múltiples de inhumación, dada la complejidad del contexto registrado. Debido a que se trata de entierros secundarios y que por lo tanto se desconoce el lapso temporal entre los eventos de muerte y los de inhumación (solo se tiene el momento del deceso del individuo de la vasija 3 , a partir de un fechado radiocarbónico), cabría la posibilidad de que los momentos de fallecimiento de cada uno de los individuos sean distintos de los de sus inhumaciones y que a su vez los momentos de los entierros también varíen en el tiempo.

Por otra parte, dada la forma de las bases de los recipientes cerámicos es imposible que pudieran mantener su verticalidad una vez depositadas en este espacio. Como no hemos hallado piedras u otros elementos que sostengan las vasijas, pensamos que pudieron excavarse pozos individuales muy cercanos entre sí. Otra posibilidad es que, si la depositación de las urnas se corresponde con un evento simultáneo, se haya excavado una fosa única del tamaño adecuado para contener los recipientes parados, de tal manera que se apoyaban unas con otras; luego terminaron levemente distanciadas por procesos de alteración posdepositacionales.

Los restos óseos fueron puestos de manera similar en todos los casos, ubicando primero los cráneos y luego los huesos de extremidades sobre ellos. Además, la sola presencia de estas partes esqueletarias nos permite pensar en el desarrollo de entierros secundarios, que involucrarían determinadas prácticas como el trozamiento de los cuerpos (si bien no se han observado marcas de corte) y la selección de las partes óseas a inhumar. Si consideramos el hecho de que algunos huesos se hallaban recubiertos por una película de color negro (aún resta determinar su composición), cabe la posibilidad de que los hayan depositado en los recipientes aún con restos de tejidos blandos. Por otra parte, nos preguntamos si otra de las prácticas vinculadas a este entierro pudo haber sido la quema de los cuerpos, un registro bastante común en el área pedemontana meridional del NOA (Berberián et al., 1977; Heredia, 1969; entre otros) y también en la porción 
septentrional (cf. Ortiz y Nieva, 2014). En tal sentido, lo primero que hay que destacar es que no se observaron señales de alteración térmica en los restos óseos. De esta manera, si bien se hallaron algunos restos de carbón (escasos y de tamaños pequeños) en los sedimentos internos de las vasijas y residuos oscuros en la superficie interna de las bases, se considera que estas no son evidencia suficiente para plantear la práctica de la cremación.

En ninguno de los casos las personas oficiantes de este ritual colocaron elementos como ajuar (a menos que estos hayan sido sustancias orgánicas que no se hayan preservado) y se desconoce si taparon las urnas, dado que, como ya ha sido mencionado, las partes superiores de las vasijas han sido alteradas por agentes antrópicos y/o naturales. Por lo tanto, los restos cerámicos y líticos hallados corresponderían a elementos que ingresarían en las vasijas por procesos postdepositacionales, posiblemente con el sedimento que las rellenaba. Con respecto a los aspectos tecno-morfológicos de las vasijas, es posible que las paredes delgadas, la ausencia de asas y las formas ovoides de éstas estén indicando una significación vinculada directamente con el uso específico de inhumar, la cual deberá ser problematizada a futuro con mayores evidencias locales y regionales.

\section{Antecedentes de otros contextos de urnas alineadas y su comparación con el caso de Anta Yacu 2}

El caso registrado en Anta Yacu 2 no parece ser el único entierro de urnas en línea. Otro contexto de similares características procede de un sitio excavado por Torres (1921) ubicado al pie de la ladera occidental de una lomada, a unos $500 \mathrm{~m}$ al norte del río Rosario (Rosario de la Frontera, provincia de Salta). Este investigador exhumó allí cuatro vasijas que enumeró del I al IV, las cuales se hallaban dispuestas en el mismo sentido de una cárcava que las puso al descubierto. Al menos tres de ellas (urnas I, II y III) se encontraban alineadas y estrechamente asociadas -separadas entre sí por 20 y $30 \mathrm{~cm}$ respectivamente-, mientras que la otra (urna IV) se encontraba a unos $6 \mathrm{~m}$ de distancia de la III (Torres, 1921, p. 6, figura 3). Una vez exhumadas las urnas, se excavaron sus sedimentos internos, se analizaron los restos recuperados y se remontaron y describieron las vasijas (Torres, 1921). Los resultados de estas tareas se sintetizan en la Tabla 3.

Según Torres (1921) los huesos se encontraron mezclados con tierra seca, tiestos y otros restos, aunque no se detalla la relación espacial entre las partes esqueletarias ni su ubicación en el interior de los recipientes. Torres (1921) sostiene que los materiales presentan caracteres tecnológicos y estilísticos que las vinculan a las urnas Tupí-guaraní y que la antigüedad de dicho sitio no debe ser mayor a la última época del período Hispano-indígena. El problema es que este autor, y otros de la misma época, atribuían varios de este tipo de contextos a la cultura o influencias culturales Tupí-guaraní, interpretación propia de la época y de la escuela Histórico-Cultural de Viena, donde todo se adjudicaba a los grupos aborígenes históricos, o como mucho le otorgaban a los sitios escasa profundidad temporal prehispánica. Analizando los datos presentados por el autor no hay una sola evidencia de restos que puedan ser asignables a esa época (por ejemplo, loza o vidrio) por lo que consideramos que estos hallazgos deben corresponder a momentos anteriores, propios de momentos prehispánicos.

El otro caso es el del sitio El Cebilar en la localidad de Monte Bello (Dpto. Río Chico, Tucumán) (Cano et al., 2002; Rodríguez et al., 2001). El sitio se ubica sobre una planicie interfluvial levemente ondulada, situada cerca de la ribera sur del río Medina, en el piedemonte oriental de la Sierra del Aconquija (Miguez, 2012). Las tareas de excavación permitieron poner al descubierto al menos tres vasijas de gran tamaño, mientras que otras dos quedaron parcialmente expuestas (Figura 6). En general poseen formas 


\begin{tabular}{|c|l|l|l|}
\hline Urna & \multicolumn{1}{|c|}{$\begin{array}{c}\text { Dimensiones, forma y tecnofactura } \\
\text { de las vasijas }\end{array}$} & \multicolumn{1}{|c|}{$\begin{array}{c}\text { No de individuos y partes } \\
\text { esqueletarias }\end{array}$} & Otros \\
\hline I & $\begin{array}{l}\text { Diámetro máx.:33 cm } \\
\text { Base cónica, cuerpo globular. Pasta } \\
\text { de color verdoso con inclusiones } \\
\text { de cuarzo. Superficies de aspecto } \\
\text { granuloso. Cocción uniforme. Sin asas. } \\
\text { Sin decoración. }\end{array}$ & $\begin{array}{l}\text { 1 individuo. Fragmentos del cráneo, } \\
\text { piezas dentarias; extremidad proximal } \\
\text { del fémur derecho y fragmentos de su } \\
\text { diáfisis; fragmentos de tibia y peroné. }\end{array}$ & $\begin{array}{l}\text { Se hallaron partes de una posible } \\
\text { tapa. Una porción de la diáfisis del } \\
\text { fémur derecho posee una coloración } \\
\text { ocre (pintura?) e "incisuras". }\end{array}$ \\
\hline II & $\begin{array}{l}\text { Base plana-cóncava, cuerpo globular. } \\
\text { Posee asas. Las características de la } \\
\text { pasta y superficie son similares a la } \\
\text { urna 1. Sin decoración. }\end{array}$ & No se hallaron restos óseos. & \\
\hline III & $\begin{array}{l}\text { Base cónica, cuerpo globular, bordes } \\
\text { evertidos. Paredes gruesas (10 mm) }\end{array}$ & $\begin{array}{l}1 \text { individuo. Partes del cráneo; } \\
\text { fragmentos de la diáfisis del húmero, } \\
\text { cúbito y radio derechos; porciones de } \\
\text { la diáfisis de ambos fémures. }\end{array}$ & $\begin{array}{l}\text { Presencia de un pequeño fragmento } \\
\text { de un cilindro de madera trabajada } \\
\text { (posible tembetá). }\end{array}$ \\
\hline IV & $\begin{array}{l}\text { Altura máx.:40 cm; diámetro máx.: } \\
\text { 25 cm. Forma general: ovoide. Base } \\
\text { redondeada, cuerpo globular, bordes } \\
\text { evertidos. Posee un asa horizontal. } \\
\text { Paredes gruesas. Sin decoración. }\end{array}$ & $\begin{array}{l}1 \text { individuo. Partes del cráneo y } \\
\text { extremidades superiores de un } \\
\text { párvulo (2-3 meses). }\end{array}$ & \\
\hline
\end{tabular}

Tabla 3. Síntesis de los de los materiales registrados y analizados por Torres (1921).

globulares, restringidas, de bases cóncavas y cuellos evertidos. Algunas poseen asas y están decoradas con incisiones y modelados antropomorfos. Por sus características formales y atributos decorativos, estas vasijas fueron asignadas a la tradición Candelaria (Cano et al., 2002), razón por la cual es muy probable que este contexto corresponda al primer milenio d.C. Por el momento, este sitio tampoco posee dataciones numéricas que permitan ubicarlo con mayor precisión cronológica. Se encontraron restos óseos humanos en al menos dos de ellas, sin presencia de ajuar. Las vasijas estaban alineadas de norte a sur y tenían cantos rodados colocados en los lados de sus bases para sostener la posición vertical de las mismas (Cano et al., 2002; Rodríguez et al., 2001). Lamentablemente no disponemos de una descripción detallada de los contextos internos de las vasijas y los restos óseos humanos no fueron analizados.

Una comparación entre los dos últimos contextos funerarios presentados con el caso del sitio Anta Yacu 2 nos permite observar algunas similitudes que deben resaltarse. La primera es la dirección en la que están alineadas las vasijas, ya que en dos casos (Anta Yacu 2 y El Cebilar) se disponen en dirección N-S. Resulta difícil llegar a una interpretación de este patrón, ya que bien podría ser un hecho casual. De todas maneras, hipotéticamente existe la posibilidad de que esa disposición esté vinculada a la dirección de un eje de referencia con relevante significación en la cosmovisión de estos grupos. En segundo término, llama la atención la similitud en cuanto a los registros óseos, al menos entre los contextos hallados en Anta Yacu 2 y los de la cuenca del río Rosario. En todas las vasijas se hallaron huesos humanos, principalmente de partes del cráneo y del esqueleto apendicular. Esto puede estar indicando varias cuestiones. Por un lado, es posible que esta presencia/ausencia de parte del esqueleto de los individuos en cada vasija se deba a problemas de preservación y procesos posdepositacionales. Sin embargo, la similitud de los registros obliga a pensar que se trataría de entierros secundarios en los que, a partir de ciertas prácticas vinculadas con el tratamiento de los cuerpos, se seleccionaron determinadas partes de los mismos para ser depositados en las vasijas, según criterios tradicionales que derivarían de sus cosmovisiones.

En tal sentido, los contenedores cerámicos con porciones anatómicas podrían estar indicando algún tipo especial de relaciones entre los ancestros y sus descendientes, tal vez vinculado con el culto a los antepasados. Esto puede implicar que el muerto sigue interactuado en la vida comunitaria de los vivos a través de la reapertura de tumbas 


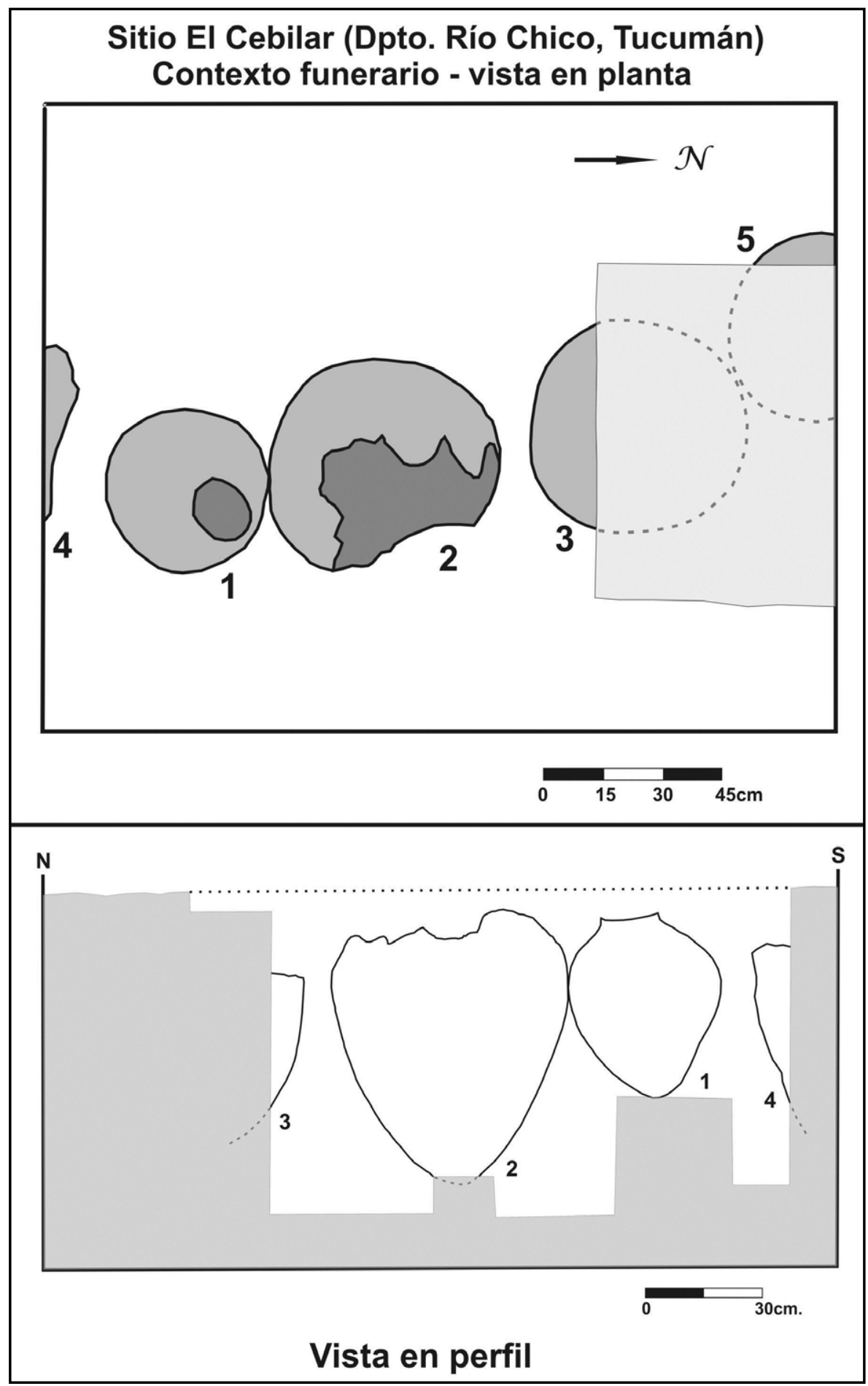

Figura 6. Contexto funerario de urnas alineadas del sitio El Cebilar. Croquis basado en gráficos originales cedidos gentilmente por el Arql. Sergio Cano.

o el procesamiento de restos humanos realizado por los deudos. Así, los entierros secundarios dan cuenta de un tratamiento espacial hacia los difuntos, cuyos huesos o partes de ellos son trasportados desde su depositación inicial a otro lugar quizás como parte de un ritual en el que los muertos se desplazan con los vivos o son mostrados cíclicamente entre ellos (Aschero, 2007). 
Un punto en común que cabe destacar para los tres casos es la cercanía de las vasijas entre sí, principalmente notable en los casos de Anta Yacu 2 y El Cebilar, La distancia entre los recipientes, considerando ambos casos, varía entre $0 \mathrm{~cm}$ (vasijas en contacto) y $20 \mathrm{~cm}$. Por su lado, en el contexto relevado por Torres (1921) la distancia de separación entre tres de las vasijas exhumadas ronda entre los 20 y $30 \mathrm{~cm}$, si bien otra urna se encontró a $6 \mathrm{~m}$ de aquellas. Estos contextos de urnas estrechamente vinculadas en un espacio acotado pueden representar una metáfora de determinados vínculos sociales entre los difuntos, tales como la pertenencia a determinados grupos dentro de una sociedad (familiares, etarios, de género u otros encargados de determinadas funciones). También es importante remarcar que en los casos analizados el rango etario (subadultos) puede estar marcando un tipo o modalidad de inhumación diferencial según la edad de los individuos dentro del grupo. Esta tendencia deberá verificarse a partir de nuevos hallazgos.

\section{Comentarios finales}

El contexto funerario del sitio Anta Yacu 2, de singular ubicación en el paisaje actual, corresponde a un espacio de inhumación de cuatro individuos en sus respectivas urnas, que habría sido construido en el marco de un mismo ritual funerario. Es posible que la cercanía de las vasijas entre sí esté relacionada con la representación simbólica de las relaciones de parentesco entre los difuntos o de su pertenencia a un grupo etario.

El registro previo de otros contextos de similares características en el piedemonte tucumano-salteño puede estar indicando la presencia de una particular modalidad prehispánica de inhumación (urnas en línea) que hasta el momento solo se registra en esta porción de las tierras bajas del NOA. Además, dicha forma de tratar a los individuos pudo haber perdurado varios siglos, si se tiene en cuenta que las urnas registradas en el sitio El Cebilar corresponderían al primer milenio d.C. De todas maneras, habría que precisar las cronologías absolutas de estos entierros.

En tal sentido, la datación radiocarbónica obtenida para al sitio Anta Yacu 2 representa una importante contribución hacia la construcción de una cronología cada vez más sólida y precisa para las tierras bajas meridionales del NOA, la cual tradicionalmente se ha sustentado en base a métodos relativos. Su importante antigüedad resulta acorde con las características del sitio (se halla enterrado a varios metros de profundidad y presenta una cerámica menos compleja que otros sitios del área de estudio que son más tardíos). Finalmente, es importante señalar que en nuestra área de estudio y en el resto de las tierras bajas tucumano-salteñas las distintas modalidades funerarias (entierros en urnas, directos y en cistas) indican una tendencia temporal marcada, y particularmente las inhumaciones en urnas se encuentran ya presentes desde un par de siglos antes de nuestra Era.

\section{Agradecimientos}

Agradecemos a los Sres. D. Villarroel, G. Ortíz y A. Flores por su ayuda en las tareas de campo y laboratorio. Al Sr. Svaldi por su gran hospitalidad. La investigación aquí presentada obtuvo su financiamiento a través del Proyecto PIUNT 26G/509. 


\section{Q Referenciadas citadas}

"Adams, B. y Byrd, J. (Eds.). (2008). Recovery, Analysis and Identification of Commingled Human Remains. Totowa: Humana Press.

" Aranda, C. y Raimundo, P. (2010). Conservación preventiva y protección patrimonial de los restos bioarqueológicos del Pukara de la Cueva (departamento de Humahuaca, Provincia de Jujuy). Trabajo presentado en XVII Congreso Nacional de Arqueología Argentina, Mendoza, Argentina.

"Aschero, C. (2007). Íconos, huancas y complejidad en la Puna sur argentina. En A. Nielsen (Ed.), Procesos Sociales Prehispánicos en el Sur Andino: La Vivienda, la Comunidad y el Territorio (pp. 259-290). Córdoba: Editorial Brujas.

» Balfet, H., Fauvet-Berthelot, M. y Monzón, S. (1992). Normas para la Descripción de Vasijas Cerámicas. México: Centre D’Études Mexicaines et Centraméricaines.

» Berberian, E. y Soria, D. (1970). Investigación arqueológica en el yacimiento de Zárate (Departamento de Trancas, Tucumán). Informe preliminar. Humanitas, 16, 165-176.

" Berberián, E., García Azcárate, J. y Caillou, M. (1977). Investigaciones arqueológicas en la región del dique el Cadillal (Tucumán-Rep. Argentina). Los primeros fechados radiocarbónicos. Relaciones de la Sociedad Argentina de Antropología, XI, 31-53.

"Binford, L. (1971). Mortuary practices: their study and their potential. Memoirs for the Society for American Archaeology, 25, 6-29.

» Botella, M., Aleman, I. y Jiménez, S. (2000). Los Huesos Humanos. Manipulación y Alteraciones. Barcelona: Ediciones Bellaterra.

»Brown, A., Grau, H., Malizia, L. y Grau, A. (2001). Los Bosques Nublados de la Argentina. En M. Kappelle y A. Brown (Eds.), Bosques Nublados de Latinoamérica (pp. 623-659). Santo Domingo: Editorial INBio.

» Buikstra, J. y Ubelaker, D. (Eds.). (1994). Standards for data collection from human skeletal remains. Fayetteville: Arkansas Archaeological Survey Research Series № 44.

»Campanella, A. (1936). Enterratorios de adultos en urnas en la región de La Toma, Departamento de Trancas (Tucumán) y nuevos paraderos en sus alrededores. Boletín del Museo de Historia Natural, 8, 17-28.

»Campillo, D. y Subirá, M. (2004). Antropología Física para Arqueólogos. Barcelona: Ariel Prehistoria.

»Cano, S., Zurita, R., Argañaráz, D., Romano, A., Rendace, S., Rodríguez, R., Sánchez, S., López, F., Gallardo, P., Reyes, D. y Di Vece, L. (2002). Rescate arqueológico de urnas funerarias en la localidad de Monte Bello, Provincia de Tucumán. Libro de Resúmenes del VII Congreso Nacional de Estudiante de Arqueología (pp. 7-8). San Pedro de Colalao.

» Caria, M. (2004). Arqueología del paisaje en la cuenca Tapia-Trancasyáreas vecinas (TucumánArgentina). (Tesis Doctoral inédita), Universidad Nacional de Tucumán, Argentina.

»Colaneri, M., Calisaya, A., Gerónimo, A., Milena, E., González, A., Vargas, V., Guardia, G., Rodríguez, A., Contreras, L., Navarro, G., Guardia, M., Guerra, W., Ruíz, D. y Gelsi, G. (2003a). Análisis del material rescatado en Horco Molle. Serie Monográfica y Didáctica, 42, 12.

" Colaneri, M., Calisaya, A., Del Bel, E., Guardia, G., Guerra, W., Leiva, A., Rodríguez Curletto, S. y Ruíz, D. (2003b). Urnas funerarias de La Cocha. Serie Monográfica y Didáctica, 42, 11. 
»Cremonte, B. y Bugliani, M. (2006-2009). Pasta, Forma e Iconografía. Estrategias para el estudio de la cerámica arqueológica. Xama, 19-23, 239-262.

»Esparrica, H. (2003). Estado actual de las investigaciones arqueológicas en el área de la comuna de San Pedro de Colalao, Tucumán, Argentina. Anales Nueva Época, 6, 242-271.

» García Azcárate, J. y Korstanje, M. A. (1995). La ocupación prehispánica de las selvas de montaña tucumanas. En A. Brown y H. Grau (Eds.), Investigación, Conservación y Desarrollo en Selvas Subtropicales de Montaña (pp. 175-182). Tucumán: Publicaciones LIEY.

»Gerónimo, A. (2003). Análisis osteológico de una urna de Río Chico. Serie Monográfica y Didáctica, 42, 16.

» Gómez, R. (1975). Arqueología del sudeste de Tucumán y sus relaciones con Santiago del Estero. Revista del Instituto de Antropología, 5, 67-72.

» Heredia, O. (1969). Arqueología de la Subárea de las Selvas Occidentales. En Actas del XXXVII Congreso Internacional de Americanistas (pp. 295-354).

» Heredia, O. (1970). Investigaciones arqueológicas en el sector meridional de la subárea de las Selvas Occidentales. (Tesis Doctoral inédita), Universidad Nacional de Córdoba, Argentina.

» Heredia, O. (1975). Investigaciones arqueológicas en el sector meridional de las Selvas Occidentales. Revista del Instituto de Antropología, 5, 73-132.

» Hodder, I. (1994). Interpretación en Arqueología. Corrientes Actuales. Barcelona: Editorial Crítica.

"Luna, L. (2008). Estructura Demográfica, Estilo de Vida y Relaciones Biológicas de Cazadores-Recolectores en un Ambiente de Desierto. Sitio Chenque I (Parque Nacional Lihué Calel, provincia de La Pampa). Oxford: BAR International Series, Archaeopress.

» Maldonado, G., Neder, L., Roldán, J. y Sampietro Vattuone, M. (2011). Caracterización geoambiental y cultural del período Formativo en Selvas Occidentales Meridionales: sitio “Horco Molle” (Dpto. Yerba Buena, Tucumán). Comechingonia, 14, 115-131.

» Martínez J., Oliszewski, N., Ribotta, E. y Sotelos, C. (1994). Primeras Investigaciones Arqueológicas en el Área de la Reserva de Flora y Fauna de Horco Molle. Trabajo presentado en III Congreso Nacional de Estudiantes de Arqueología. Rosario, Argentina.

» Miguez, G. (2005). Dinámica local y relaciones interétnicas: nuevas investigaciones y replanteo de la problemática arqueológica del piedemonte tucumano de la Sierra San Javier. Dpto. de Yerba Buena. Pcia. de Tucumán. (Tesis de Licenciatura inédita), Universidad Nacional de Tucumán, Argentina.

» Miguez, G. (2006). Sistema de ocupación prehispánica y paisaje social en un sector del piedemonte de la sierra San Javier. Tucumán. Argentina. Canindé, 8, 67-94.

" Miguez, G. (2010). Historia del Instituto de Arqueología y Museo en Horco Molle. En C. Aschero, P. Arenas y C. Taboada (Eds), Rastros en el camino...Trayectos e identidades de una Institución. Homenaje a los 80 años del IAM-UNT (pp. 329-338). Tucumán: EDUNT.

» Miguez, G. (2012). Lo pasado...arado: impacto del desarrollo agrícola moderno sobre el patrimonio arqueológico del Área Pedemontana Meridional de la Provincia de Tucumán (Argentina). Comechingonia, 16(2), 31-54.

» Miguez, G. y Caria, M. (2010). La ocupación prehispánica de la Sierra San Javier y espacios aledaños (Tucumán, Argentina). En R. Grau, H. Bomba, H. Hernández y L. Paolini (Eds.), Ecología Regional de una Interfase Natural-Urbana. La Sierra de San Javier y el Gran San Miguel de Tucumán (pp. 121-137). Tucumán: EDUNT. 
» Miguez, G. y Caria, M. (2015). Paisajes y prácticas sociales en las selvas meridionales de la Provincia de Tucumán ( $1^{\circ}$ milenio D.C.). En M. A. Korstanje, M. Lazzari, M. Basile, F. Bugliani, V. Lema, L. Pereyra Domingorena y M. Quesada (Eds.), Crónicas Materiales Precolombinas. Arqueología de los Primeros Poblados del Noroeste Argentino (pp. 111-148). Buenos Aires: Sociedad Argentina de Antropología.

»Miguez, G.y Caria, M. (2016). Nuevos aportes a la cronología de la ocupación prehispánica del piedemonte oriental de la Sierra San Javier. Primeros fechados absolutos. Serie Monográfica y Didáctica, 54, 2019-2024.

» Miguez, G. y Ortiz, G. (2011). Hallazgo de un nuevo sitio y rescate de un singular contexto funerario en horco molle. Serie Monográfica y Didáctica, 52, 167.

"Mondini, M. (2003). Formación del registro arqueofaunístico en abrigos rocosos de la Puna argentina. Tafonomía de carnívoros. (Tesis Doctoral inédita), Universidad de Buenos Aires, Argentina.

"Ortiz G. y Nieva, L. (2014). Morir en el Valle de San Francisco. Practicas funerarias, termoalteración y estrategias de memorizacion en la selva pedemontana de las Yungas del NOA. Zeitschrifffür Archäologie Aussereuropäischer Kulturen, 6, 247-276.

»Pantorrilla, M. y Núñez Regueiro, V. (2006). Investigaciones arqueológicas en la zona de Escaba, provincia de Tucumán: asentamientos Condorhuasi y Aguada en las Yungas. Intersecciones en Antropología, 7, 235-245.

»Parker Pearson, M. (1982). Mortuary practices, society and ideology: an ethnoarchaeological study. En I. Hodder (Ed.), Symbolic and Structural Archaeology (pp. 99-113). Cambridge: Cambridge University Press.

" Parker Pearson, M. (1999). The Archaeology of Death and Burial. Texas: Texas A\&M University Press.

»Primera Convención Nacional de Antropología. (1966). Publicaciones Nueva Serie del Instituto de Antropología 1. Córdoba: Universidad Nacional de Córdoba, Dirección General de Publicaciones.

»Rendace, S., Argañaráz Fochi, D., Cordomí, C. y Cuenya, P. (2006). Pedología y niveles de ocupación arqueológica. En Actas III Congreso Argentino de Cuaternario y Geomorfología (pp. 827-836). Córdoba: Universidad Nacional de Córdoba.

» Rodríguez, R., Zurita, R., Romano, A., Sánchez, S., Monti, L. y Gómez Augier, J. (2001). Las urnas funerarias del Cebilar (STucRCh1). Informe preliminar. Libro de Resúmenes del XIV Congreso Nacional de Arqueología Argentina (pp. 105). Tucumán.

» Roviere, H. y Delmas, A. (1965). Anatomie Humanie. Paris: Masson.

» Rydén, S. (1936). Archaeological researches in the Departament of La Candelaria (prov. Salta, Argentina). En W. Kaudern (Ed.), Ethnological Studies 3 (pp. 7-305). Gotemburgo: Gothemburg Museum.

》Scheuer L. y Black, S. (2000). Developmental Juvenile Osteology. Nueva York: Academic Press.

»Srur, G. (2008). Estudio de las urnas funerarias en la Cultura La Candelaria, sitio El Cadillal (Prov. de Tucumán). (Tesis de Licenciatura inédita). Universidad Nacional de Córdoba, Argentina.

» Tainter, J. (1978). Mortuary Practices and the Study of Prehistoric Social Systems. En M. Schiffer (Ed.), Advances in Archaeological Method and Theory (pp. 105-141). Nueva York: Academic Press.

» Tartusi, M. y Núñez Regueiro, V. (2003). Procesos de interacción entre poblaciones de los valles intermontanos del noroeste argentino y las del piedemonte. En P. Cornell y P. Stenborg (Eds.), Local, Regional, Global: Prehistoria, Protohistoria e Historia en los Valles Calchaquíes, (pp. 43-62). Gotemburgo: Gothemburg Museum. 
"Torres, L. (1921). Arqueología de los Valles orientales de la Provincia de Salta. Urnas funerarias en la cuenca del río Rosario (Departamento de Rosario de la Frontera). Revista del Museo de La Plata, 25, 1-14.

"Ubelaker, D. (1989). Human Skeletal Remains: Excavation, Analysis, Interpretation. Washington: Taraxacum.

"White, T. y Folkens, P. (1991). Human Osteology. San Francisco: Academic Press. 